\title{
Loose Leaf Lettuce Quality Grown in Two Production Systems
}

\author{
Luis L.Travieso \\ Adrian P. Leon, MSc. \\ Veronica R. Logegaray,Esp. \\ Diana Frezza, $M S c$. \\ Angel Chiesa, $D$. \\ University of Buenos Aires, Argentina
}

doi: 10.19044/esj.2016.v12n30p55 URL:http://dx.doi.org/10.19044/esj.2016.v12n30p55

\begin{abstract}
Horticultural crops have a strong impact on human nutrition. Lettuce is the most important leafy vegetable in Argentina and it is cultivated mainly in green belts, in greenhouses or open field. The aim of this study was to evaluate growth and phytonutrients concentration of leaf lettuce under greenhouse and field production. Crop establishment was made from seedlings produced in a commercial greenhouse. Loose lettuce cv. Brisa was used for field and greenhouse growth. Experimental design with complete random block with 4 replicates per treatment was used. Fresh and dry weights of shoot, number of leaves, color, ascorbic acid, chlorophyll content were measured. Absolute and relative growth rate and commercial yield were calculated. Lettuce grown under greenhouse system showed, as expected, a higher value of fresh and dry weight, number of leaves, leaf area, yield and absolute and relative growth rate. Ascorbic acid value of the leaves decreased during lettuce growth in both production systems. Chlorophyll content was higher in the greenhouse cultivation but the antioxidant capacity was lower in lettuce leaves from greenhouse than the leaves grown on open field.
\end{abstract}

Keywords: Leafy vegetable, greenhouse, ascorbic acid, antioxidant, chlorophyll

\section{Introduction}

Lettuce is a leafy vegetable grown troughout the country around urban centers and in specialized areas and it is grown under greenhouse or field conditions. There is dependence between crop growth and weather conditions (Scaglia et al., 2003). Lettuce is traditionally field grown crop but 
recently greenhouse production increased too much due to high quality of product (Maroto, 2000). Commercial yields of greenhouse lettuce production range between 20-50 tn.ha ${ }^{-1}$ (Ferratto, 1995).

Quality of horticultural products is evaluated in terms of: hygienicsanitary, nutritional, technological and organoleptic quality (Gaviola, 1996).

Lettuce, like other leafy vegetables, is known for its supply of vitamin C, B1, B2, folic acid, high in magnesium and few sodium (Lee and Kader, 2000). Furthermore, also contains many antioxidant compounds, such as: carotenoids, polyphenols and fiber (Serafini et al., 2002) and has significant quantities of calcium and iron (Romani et al., 2002). Many studies suggest that phytonutrients have positive effects in preventing cancer, cardiovascular disease and reducing the incidence of other chronic disease (Lee and Aedin, 2006).

Many preharvest factors can affect postharvest quality and nutritional value of vegetables (Weston y Barth, 1997). Light and temperature have a strong influence on chemical composition of vegetables (Klein and Perry, 1982). These variations are due to the fact that phytonutrients are encoded by a large number of genes and share biosynthesis pathways whose regulation is at least partially regulated environmentaly (Hirschberg 2001; Lichtenthaler 2007; Vogt 2010).

Vitamin C, including ascorbic acid and dehydroascorbic acid, is one of the most important compound contributing to nutritional quality in many vegetable crops and has numerous biological activities in the human body (Lee y Kader, 2000) and it is a primary source of dietary antioxidants (Martínez-Sánchez et al., 2008).

Climate and cultural conditions influence the content of vitamin $\mathrm{C}$ (Lisiewska and Kmiecik,1996). Light also affect ascorbic acid content, generally lower light intensity during growth less ascorbic acid content in plant tissues (Harris, 1975). Lee and Kader (2000) report that between preharvest factors, genotype, light intensity and temperature are the most important factors determining final content in vegetables.

Leafy vegetables also contain several types of photosynthetic pigments, including cholorophyll and carotenoids (Kimura y RodríguezAmaya, 2002). The estructure of these pigments produces specific color, which is one of the attributes of visual quality (Xue y Yang, 2009). It is widely known that the chlorophyll content of the leaf is an important testing parameter for determine plant condition, for example, it can be used as an index for plant productivity and photosynthetic potential (Carter, 1998; Penuelas et al., 1995). Furthemore, chlorophyll content gives an indirect estimate of nutrient status because much of the nitrogen is part of leaf chlorophyll (Penuelas et al., 1995). However, its content is also closely 
related to various types of stress and senescence (Carter et al., 1996; Gitelson and Merzlyak, 1994; Penuelas et al., 1995).

Many phenolic compounds, including flavonoids present in lettuce, have been extensively studied because of its antioxidant properties (Altunkaya et al., 2009; Llorach et al., 2008). In plants, they are related to various defense mechanisms, therefore, environmental factors such as light, temperature, humidity, and other internal and genetic differences, nutrients, hormones, etc contribute to its shyntesis (Hahkonen et al., 2001).

The aim of this study was to evaluate if culture condition affect growth and nutritional quality of loose leaf lettuce. Nutritional quality is of great interest, as this aspect is being increasingly considered among consumers who are willing to get horticultural products of higher nutritional quality, promoting a growing demand.

\section{Material and Methods}

Crop establishment was made with seedlings produced in a comercial greenhouse. Transplant was performed 40 days after sowing in two different systems: greenhouse and open field. Cultivation was carried out at a density of 16 plants.m- ${ }^{2}$ ( 0.25 between rows and plants), after that crop management was similar to one commercial, regular watering by hand to keep the soil with adequate water supply.

\section{Treatments and experimental design}

Loose lettuce cv. Brisa was used for open field and greenhouse crop. Experimental design with complete random block with four replicates per treatment was used. Data collection was performed four times during growth period: initial time (0 day, transplant day) and 42, 69 and 97 days after transplant. Each moment three randomly selected plants per replicate and three leaves for different position were taken for determination of ascorbic acid, chlorophyll and antioxidant capacity. Procedures and calculations proposed by Hunt (1978, 1982) were used.

To determine fresh and dry weight of the shoot an electronic balance Scout Pro-SP2001 was used. Dry matter was calculated using the following equation:

$\%$ Dry matter $(\% \mathrm{DM})=($ dry weight $(\mathrm{g}) /$ fresh weight $(\mathrm{g})) * 100$

Number of leaves was recorded counting the number of leaves larger than $2 \mathrm{~cm}$ and leaf area was estimated by drawn the perimeter of each individual leaf in A4 paper, trimmed around the perimeter and finally since A4 area and weight was known leaf area was calculated. Absolute and relative growth rate and commercial yield were calculated.

Ascorbic acid was measured according to a combination of methods proposed by_Vicente et al. (2006) y Kvesitadze et al. (2001). Color 
parameters were measured by the Hunter Lab co-ordinates by a tristimulurs colorimeter (model CR 300, Minolta Corporation, Japan) and a CIE standard illuminant D65. The colorimeter was calibrated with a standard white tile $(Y=95.3, x=0.3133, y=0.3197)$. Color was exoressed using $L^{*}, a^{*}$ and $b^{*}$ parameters.

Antioxidant capacity was determined by techniques adapted from Brand-Williams et al., (1995); Leong y Shui, (2001); and Lim y Quah, (2007).

For determination of total chlorophyll technique used by William et al. (1984) was employed.

Data were analyzed using analysis of variance, using Tukey test at $5 \%$ for comparison between treatments. Infostat statistical program was used.

\section{Results and Discussion}

Fresh weight (FW) showed significant differences between the average values of greenhouse and field, being higher in the greenhouse. Lettuce grown in greenhouse had higher FW at 69 days after transplanting and could be harvested at that moment because they reached commercial weight. Lettuce grown in crop field had less FW during the growing stage (Figure 1). These results agree with Maroto (2000) who reported that greenhouse vegetable production tends to increase production levels, following the best conditions of physical environment. Differences in the growth period occur in response to temperature and radiation. Growth rate is accelerated by high temperatures and higher irradiance (Wien, 1997). Temperatures in the greenhouse were greater during the crop growth cycle, therefore, the growth rate was higher and the cycle was reduced.

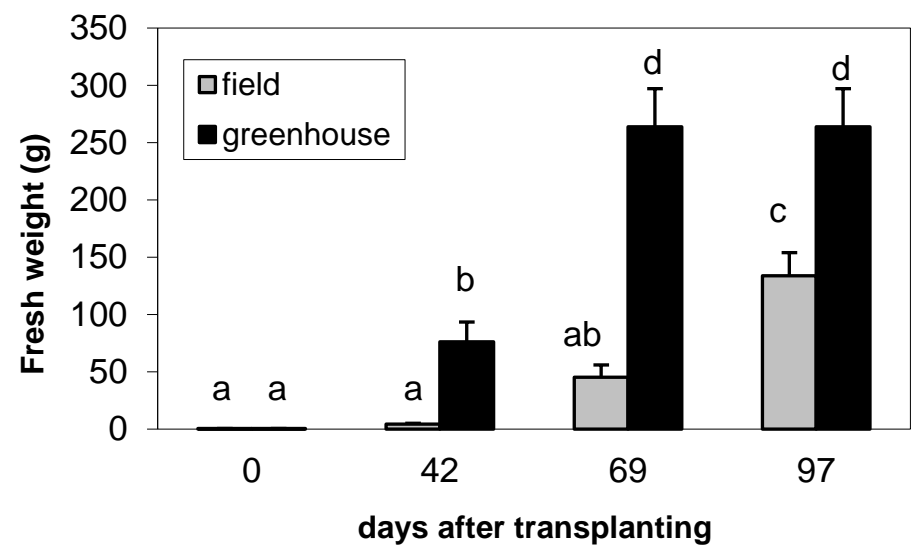

Figure1. Fresh weight of lettuce in two growing systems (open field and greenhouse) during growth cycle (0, 42, 69 and 97 days after transplanting). Different letters means significant differences. 
Dry weight showed significant differences between growing systems, with a higher value in greenhouse. Lettuce cultivated on field presented lower dry weight at harvest (Figure 2).

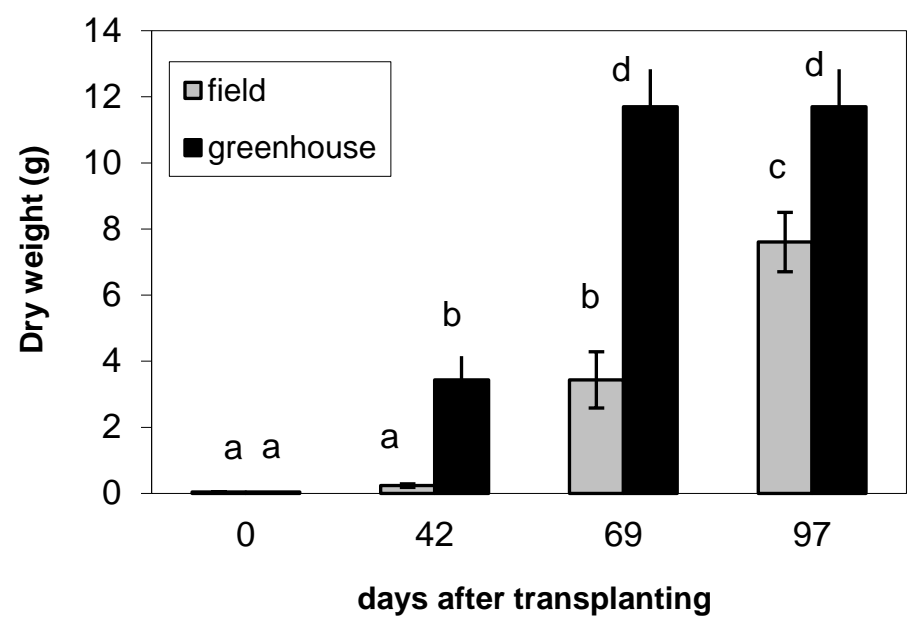

Figure 2. Dry weight of lettuce growing in two different systems (open field or greenhouse). Different letters means significant differences $(\boldsymbol{\alpha}=\mathbf{0 . 0 5})$.

Dry matter decreased from transplant to harvest but with lower percentage in the greenhouse at harvest (Figure 3). Stanley (1989) reported that plants decrease the content of dry matter, vitamin C, potassium, magnesium, iron and zinc when progresses at their stage of development.

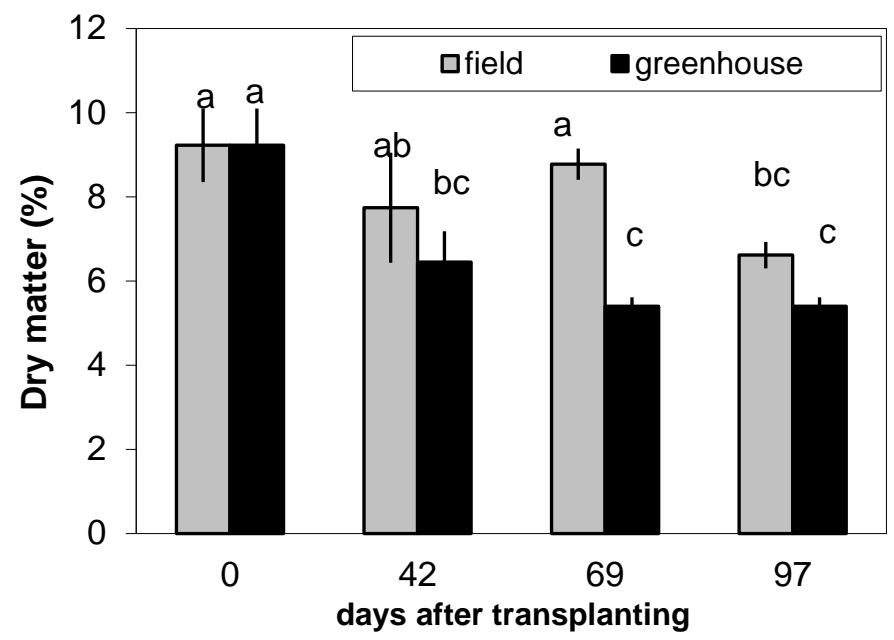

Figure 3. Lettuce dry matter in two systems (open field and greenhouse). Different letters means significant differences $(\alpha=0,05)$. 
Plants cultivated in greenhouse had more leaves during the growing season, however the same number of leaves were reached in open field system at harvest (Figure 4).

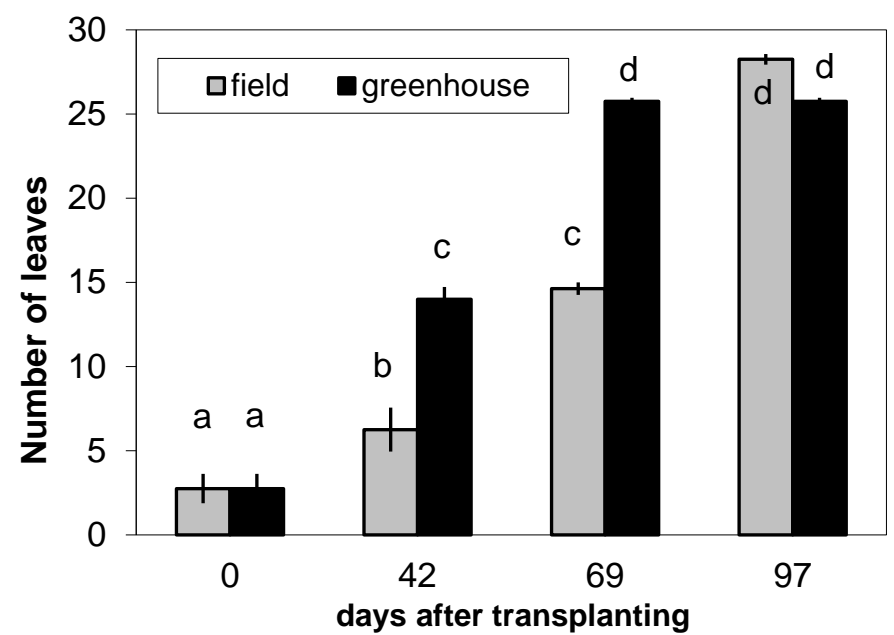

Figure 4. Number of leaves per plant in lettuce grown in two systems: open field and greenhouse. Different letters means significant differences $(\alpha=0,05)$.

Leaf area of lettuce in greenhouse was significantly higher than open field treatment from 42 days after transplanting (Figure 5).

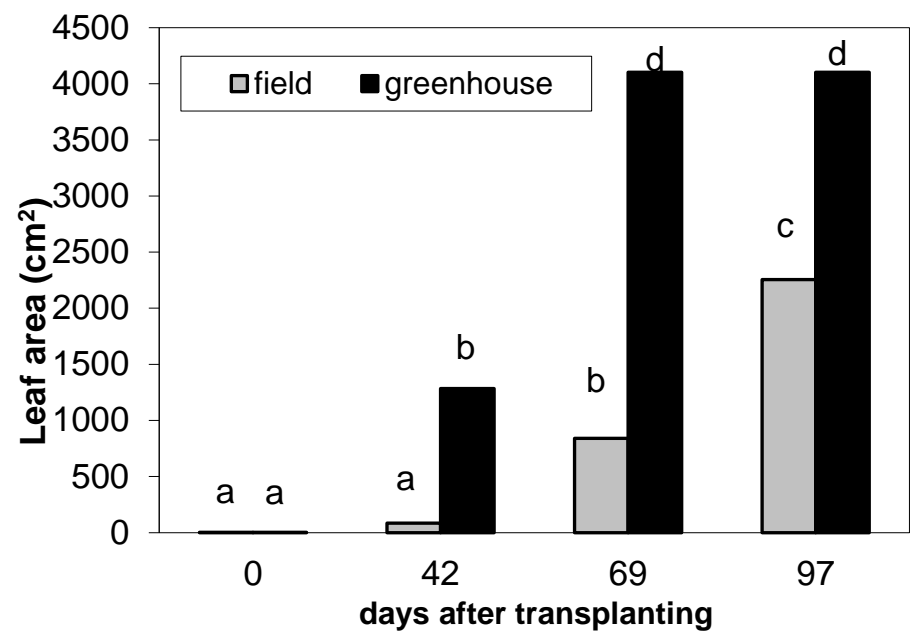

Figure 5. Leaf area of lettuce growing in two systems (open field and greenhouse).

Different letters means significant difference $(\alpha=0,05)$.

Absolute growth rate showed a significant difference between production system and time with the highest value in the greenhouse at 69 days after transplanting. It was also observed that field had no differences 
from 0 to 69 days (Figure 6). It may be because the temperature was lower for crop growth on open field. Relative growth rate had differences between systems and time.

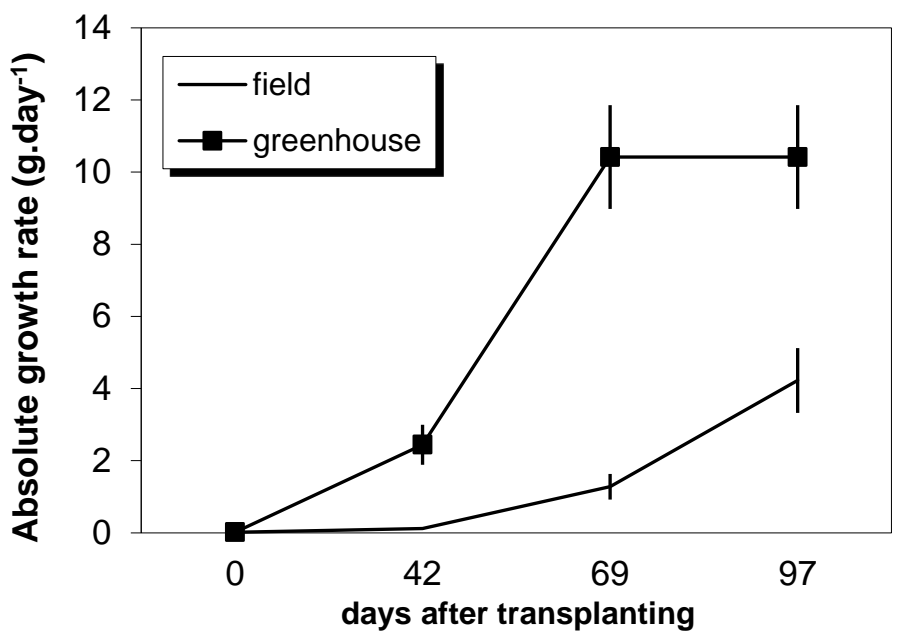

Figure 6. Absolute growth rate of lettuce in two growing systems (open field and greenhouse).

Lettuce yield presented significant differences being almost twice in greenhouse (39 T.ha' $\left.{ }^{-1}\right)$ than on field $\left(20 \mathrm{~T} \mathrm{ha}^{-1}\right)$.

Table 1. Color parameters $\left(\mathrm{L}^{*}, \mathrm{a}^{*}, \mathrm{~b}^{*}\right)$ of lettuce during growing in greenhouse and on field

\begin{tabular}{|c|c|c|c|c|c|}
\cline { 3 - 6 } \multicolumn{2}{c|}{} & \multicolumn{4}{c|}{ Days after transplanting } \\
\hline \multirow{2}{*}{$\mathrm{L}^{*}$} & Syrameter & 0 & 42 & 69 & 97 \\
\cline { 2 - 6 } & Open Field & $62.55 \mathrm{a}$ & $57.29 \mathrm{~b}$ & $60.67 \mathrm{ac}$ & $61.62 \mathrm{ac}$ \\
\cline { 2 - 6 } $\mathrm{a}$ & Greenhouse & $62.55 \mathrm{a}$ & $59.21 \mathrm{bc}$ & $61.45 \mathrm{ac}$ & $61.45 \mathrm{ac}$ \\
\hline \multirow{2}{*}{$\mathrm{b} *$} & Open Field & $26.6 \mathrm{a}$ & $24.95 \mathrm{~b}$ & $24.69 \mathrm{~d}$ & $23.89 \mathrm{~cd}$ \\
\cline { 2 - 6 } & Greenhouse & $26.6 \mathrm{a}$ & $21.46 \mathrm{c}$ & $23.32 \mathrm{c}$ & $23.32 \mathrm{c}$ \\
\hline & Open Field & $45.81 \mathrm{a}$ & $42.32 \mathrm{~b}$ & $40.38 \mathrm{~b}$ & $40.63 \mathrm{~b}$ \\
\cline { 2 - 6 } & Greenhouse & $45.81 \mathrm{a}$ & $45.32 \mathrm{~b}$ & $41.38 \mathrm{~b}$ & $41.38 \mathrm{~b}$ \\
\hline
\end{tabular}

Different letter means significant difference in the same line and between treatments for the same parameter.

Among the greenhouse and open field treatments no significant differences for brightness $(\mathrm{L} *)$ were recorded. There were significant differences between growing dates of lettuce with lower brightness at 42 days ( $\mathrm{L} *$ value between 57.29 and 59.21 on average).

Significant differences between treatments and sampling dates for a * value were found. Higher a * (green) was observed during transplanting and $a^{*}$ values were significantly higher on field at 42, 69 and 97 days .

No significant differences were found for $b^{*}$ parameter. The date of transplant showed greater value $(b *=45.81$ ) than any other 
Significant differences for estimating total chlorophyll in lettuce leaves ( $\mathrm{p}<0.0001$ ) were found at harvest being higher for plants of greenhouse $\left(0.25 \mathrm{mg}^{-1} \mathrm{~g}^{-1}\right)$ that open field $\left(0.16 \mathrm{mg} \cdot \mathrm{g}^{-1}\right)$ (Figure 7$)$.

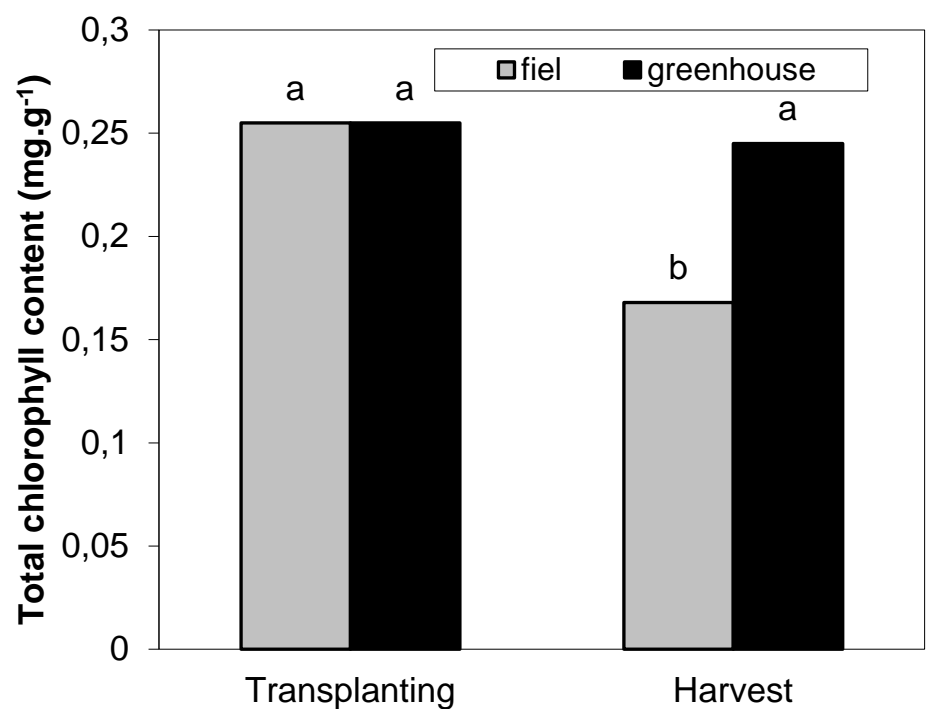

Figure 7. Total chloropyll content $\left(\mathrm{mg}^{\mathrm{g}} \mathrm{g}^{-1}\right.$ ) of lettuce in two growing systems (field and greenhouse) at two different moments (transplanting and harvest).

The ascorbic acid content presented significant differences between treatments. The ascorbic acid content of lettuce was higher in open field than in greenhouse at the beginning of the growing season but lower at harvest. Preharvest factors, genotype, light intensity and temperature are the most important facts determining the final content of ascorbic acid in vegetables (Lee and Kader, 2000). The climate and cultural conditions influence the content of vitamin C. Higher content of vitamin C to harvest is expected with higher light intensity during crop growth (Lisiewska and Kmiecik, 1996). The data are consistent with the literature cited.

Significant differences were found among dates with a decrease in ascorbic acid content of lettuce leaves from transplanting to harvest (Figure 8). This is consistent with Stanley (1989) who reported that as the plant progresses in its development stage, reduces the content of dry matter, vitamin $\mathrm{C}$, potassium, magnesium, iron and zinc. 


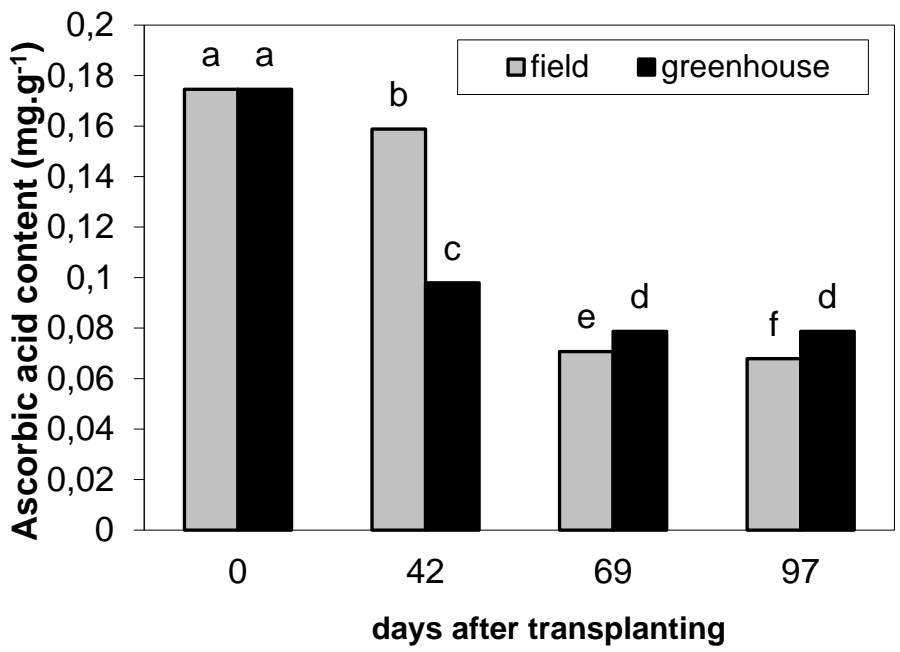

Figure 8 Ascorbic acid content of leaves in lettuce grown in two systems: open field and greenhouse. Different letters means significant difference $(\boldsymbol{\alpha}=\mathbf{0 , 0 5})$.

Significant differences in antioxidant capacity were found. Light intensity was lower in the greenhouse, so it would have expected a lower level of antioxidant capacity. Time also showed statistically significant differences ( $\mathrm{p}<0.0001)$ being 69 days the highest value. At the middle of the growing season (42 days) field 42 had the highest value of antioxidant capacity (Figure 9).

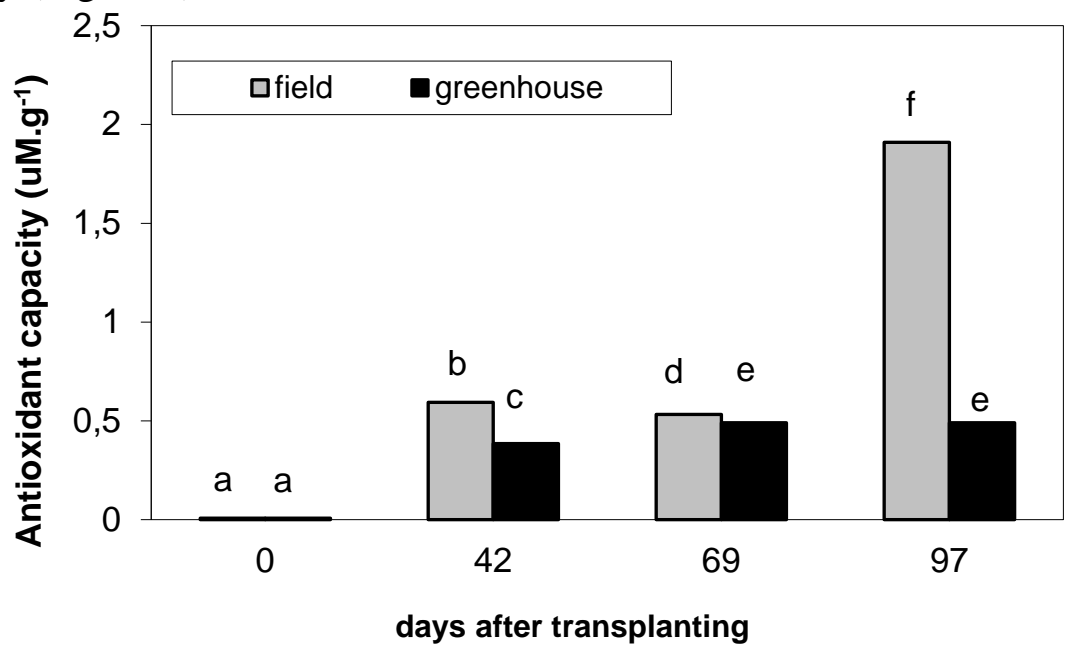

Figure 9. Antioxidant capacity (uM.g ${ }^{-1}$ ) in lettuce leaves grown in two systems: open field and greenhouse Different letters means significant difference $(\boldsymbol{\alpha}=\mathbf{0 , 0 5})$. 


\section{Conclusion}

Lettuce grown under greenhouse system showed, as expected, a higher value of fresh and dry weight, number of leaves, leaf area, yield and absolute and relative growth rate. Ascorbic acid value of the leaves decreased during lettuce growth in both production systems. The values of chlorophyll and antioxidant capacity were higher in the greenhouse cultivation.

\section{References:}

1. Altunkaya, A., Becker E.M., Gökmen V., and Skibsted L.H. 2009. Antioxidant activity of lettuce extract (Lactuca sativa) and synergism with added phenolic antioxidants. Food Chemistry 115: 163-168.

2. Brand-Williams W., Cuvelier M.E., and Berset C. 1995. Use of a free radical method to evaluate antioxidante activity. LWT Food Science and Technology. 28 (1):25-30.

3. Carter, G.A., 1998. Reflectance wavebands and indices for remote estimation of photosynthesis and stomatal conductance in pine canopies. Remote Sensing of Environment. 63 (1):61-72.

4. Carter, G.A., Cibula, W.G. and Miller, R.L., 1996. Narrow-band reflectance imagery compared with thermal imagery for early detection of plant stress. Journal of Plant Physiology. 148: 515-522.

5. Ferratto, J. 1995. Producción de hortalizas en invernáculo. Cultivo de la lechuga. INTA. Curso a Distancia. Módulo 5: 79.

6. Gaviola, S. 1996. Factores de manejo que inciden sobre la calidad de las hortalizas. Avances en Horticultura 1 (1):4 -18.

7. Gitelson, A.A. and Merzlyak, M.N., 1994. Spectral reflectance changes associate with autumn senescence of Aesculus hippocastanum L. and Acer platanoides L. leaves. Spectral features and relation to chlorophyll estimation. Journal of Plant Physiology. 143 (3): 286-292.

8. Harris, R. S. 1975. Effects of agricultural practices on the composition of foods. In: Harris, R.S, Karmas, E. (Eds.), Nutritional Evaluation of Food Processing, 2nd edition. AVI, Westport, CT, p. 33-57.

9. Hahkonen M.; Hopia, A. and Heinomen, M. 2001. Berry Phenolics and their Antioxidant Activity. Journal of Agricultural and Food Chemistry. 49 (8): 4076-4082.

10. Hirschberg J. 2001. Carotenoid biosynthesis in flowering plants. Current Opinion in Plant Biology. 4 (3): 210-218.

11. Hunt, R. 1978. Plant growth analysis. Edward Arnold, London. 67 p.

12. Hunt, R. 1982. Plant growth curves. The functional approach to plant growth analysis. Edward Arnold, London. 248 p. 
13. Kimura, M. and Rodriguez-Amaya, D.B., 2003. Carotenoid composition of hydroponic leafy vegetables. Journal of Agricultural and Food Chemistry. 51 (9): 2603-2607.

14. Kimura, M.and Rodriguez-Amaya, D. B. 2002. A scheme for obtaining standards and HPLC quantification of leafy vegetable carotenoid. Food Chemistry. 78 (3): 389-398.

15. Klein, P. B. and Perry, A. K. 1982. Ascorbic acid and vitamin A activity in selected vegetables from different geographical areas of the United States. Journal of Food Science. 47 (3): 941-945.

16. Kvesitadze G. II, Kalandiya A. G., Papunidze S. G. and Vanidze M. R. 2001. Identification and quantification of ascorbic acid in kiwi fruit by High - Performance Liquid Chromatography. Applied Biochemist ry and Microbiology. 37 (2): 215- 218.

17. Lee, H. and Aedin, C 2006. A review of the health care potential of bioactive compounds. Journal of the Science of Food and Agriculture. 86 (12): 1805-1813.

18. Lee, S. K.and Kader, A. A. 2000. Preharvest and postharvest factors influencing vitamin $\mathrm{C}$ content of horticultural crops. Postharvest Biology and Technology. 20 (3): 207-220.

19. Leong, L.P.and Shui, G. 2002. An investigation of antioxidant capacity of fruits in Singapore markets. Food Chemistry. 76 (1): 6975.

20. Lim Y.Y. and Quah E.P. 2007. Antioxidant properties of different cultivars of Portulaca oleracea. Food Chemestry. 103 (3): 734-740

21. Lichtenthaler H.K. 2007. Biosynthesis, accumulation and emission of carotenoids, $\alpha$-tocopherol, plastoquinone, and isoprene in leaves under high photosynthetic irradiance. Photosynthesis Research. 92 (2): 163-179.

22. Lisiewska, Z. and Kmiecik, W. 1996. Effects of level of nitrogen fertilizer, processing conditions and period of storage of frozenbroccoli and cauliflower on vitamina $C$ retention. Food Chemistry. 57 (2): 267-270.

23. Llorach, R.; Martinez-Sanchez, A.; Tomas-Barberan, F. A.; Gil, M. I.and Ferreres, F. 2008. Characterisation of polyphenols and antioxidant properties of five lettuce varieties and escarole. Food Chemistry. 108 (3): 1028-1038.

24. Maroto, J. V.2000. Horticultura Herbácea Especial. Ed. MundiPrensa. Madrid. España. 566 p.

25. Martinez-Sanchez A., Gil-Izquierdo A., Gil M.I. and Ferreres F. 2008. A comparative study of flavonoid compounds, vitamin C, and antioxidant properties of baby leaf Brassicaceae species. Journal of Agricultural and Food Chemistry. 56 (7): 2330-2340. 
26. Penuelas, J., Filella, I. and Baret, F., 1995. Semi-empirical indices to assess carotenoids/chlorophyll a ratio from leaf spectral reflectance. Photosynthetica. 31: 221-230.

27. Romani A., Pinelli P., Galardi C., Sani G., Cimato A. and Heimler D. 2002. Polyphenols in greenhouse and open-air-grown lettuce. Food Chemistry. 79 (3): 337-342.

28. Scaglia. E, Vega. M.A and Salto. C. Anuario 2003. Agronomía. Abril 2004. Lechuga tipo “de hoja”. Prácticas para una producción contínua a campo. Instituto Nacional de Tecnología Agropecuaria. Estación Experimental Rafaela.

29. http://inta.gob.ar/rafaela/info/documentos/anuario2003/a2003_p136.h tm

30. Serafini M., Bugianesi R., Salucci M., Azzini E., Raguzzini A.and Maiani G. 2002. Effect of acute ingestion of fresh and stored lettuce (Lactuca sativa) on plasma total antioxidant capacity and antioxidant levels in human subjects. British Journal of Nutrition. 88 (6): 615623.

31. Stanley, R. 1989. The influence of temperature and packaging material on the post harvest quality of Iceberg Lettuce. Acta Horticultarae 224. 171-180.

32. Vicente, A R., Martinez, G A., Chavez, A R. and Civello P. 2006. Effect of heat treatment on strawberry fruit damage and oxidative metabolism during storage. Postharvest Biology and Technology. 40 (2): $116-122$.

33. Vogt T. 2010. Phenylpropanoid biosynthesis. Molecular Plant. 3 (1): 2-20.

34. Weston, L.A. and Barth, M.M. 1997. Preharvest Factors affecting Postharvest quality of vegetables. HortScience. 32 (5): 812-816.

35. Wien, H.C. 1997. The physiology of vegetable crops. CAB Internacional. UK. 662 p.

36. William P., Inskeep and Bloom, P.R.. 1984. Extinction coefficients of chlorophyll a and b in $N, N$-dimethylformamide and $80 \%$ acetone. Plant physiology. 77 (2): 483-485.

37. Xue, L. and Yang, L. 2009. Deriving leaf chlorophyll content of green-leafy vegetables from hyperspectral reflectance. ISPRS Journal of Photogrammetry and Remote Sensing. 64 (1): 97-106. 